\title{
A crítica ao eruditismo no jovem Nietzsche
}

\section{Felipe Luiz Gomes Figueira}

Professor do IFPR (campus Paranavaí) e do Colégio Nobel

José Fernandes Weber

Professor do departamento de Filosofia da Universidade Estadual de Londrina

\section{RESUMO}

O objetivo deste artigo é investigar a crítica ao eruditismo no jovem Nietzsche. Analisaremos, para tanto, a influência de Schopenhauer em Nietzsche e os conceitos de ampliação e redução máximas da cultura. A partir destas considerações, objetivamos apreender de que maneira o tipo de educação erudita pode impedir o aparecimento e a efetivação de um tipo de homem e de cultura superiores.

Palavras-chave: Nietzsche; educação; eruditismo.

\begin{abstract}
The purpose of this paper is to investigate young Nietzsche's critique of eruditism. For this, we will analyse Schopenhauer's influence upon Nietzsche and the concepts of maximal ampliation and reduction of culture. From this considerations our purpose is to apprehend the way the eruditist education can to obstruct the appearing and effectuation of a higher model of man and culture.
\end{abstract}

Keywords: Nietzsche; education; eruditism. 
$\mathrm{F}$ riedrich Nietzsche, já no seu prefácio às Conferências sobre o futuro dos nossos estabelecimentos de ensino ${ }^{1}$, a fim de evitar incompreensões, faz questão de deixar claro quais "estabelecimentos de ensino" são analisados e combatidos. Assim, ele afirma:

É o futuro destas instituições alemães que nos deve reter, quer dizer, o futuro da escola primária alemã, da escola técnica alemã, do ginásio alemão, da universidade alemã: fazendo isso, renunciamos provisoriamente a qualquer comparação e a qualquer julgamento de valor, como se as condições que são as nossas, em relação às demais de outros povos cultos, fossem modelos universais jamais superados (NIETZSCHE, 2003a, p. 42).

De início, parece despropositada a preocupação com o futuro das instituições alemãs responsáveis pela educação, afinal, não se tornaram elas “modelos universais jamais superados”? Ao menos é esse o juízo partilhado na Europa na segunda metade do século XIX. Contudo, não é esse o modo como Nietzsche pensa a situação das instituições educativas alemãs, a ponto de identificar, no próprio núcleo de sua constituição e organização, duas tendências, ao seu juízo bárbaras, que, a medida em que se solidificam, promovem a própria destruição da cultura, na medida em que operam pela obstrução do cultivo da singularidade e da diferença. Ampliação máxima da cultura e redução e enfraquecimento da cultura, são os nomes de concepções e práticas distintas do que significam cultura e educação, mas que alcançam um mesmo resultado: destruição da cultura.

A essas tendências, Nietzsche destinará duras críticas, pois geram, segundo sua perspectiva, uma "cultura mentirosa", e são opostas aos princípios aristocráticos, seletivos, da natureza. Ampliar e enfraquecer a

${ }^{1}$ Trata-se aqui das cinco conferências escritas por Nietzsche a respeito do futuro dos estabelecimentos de ensino alemães e ministradas na Universidade de Basiléia, a convite da Sociedade Acadêmica de Basiléia, no início do ano de 1872, entre os meses de janeiro e março. Para maiores esclarecimentos acerca destas conferências, cf. DIAS (1991, p. 38) e SANTOS (1993, p. 31-32). 
cultura de modo a que ela se torne mera serva do Estado, mediante utilitarismo e egoísmo, nem de longe corresponde aos objetivos nobres e desinteressados da natureza, que se justifica nos "exemplares superiores", nos "gênios", e não em sujeitos movidos por uma lógica banalizadora e egoísta. Contra essas correntes, Nietzsche opõe-se veementemente, escreve conferências para "leitores calmos", que não foram tragados "pela pressa vertiginosa da nossa época precipitada", e, é válido lembrar, não propõe algo comparável a um "projeto político pedagógico", nenhuma ordem de privilégio para si e para os seus - de modo a não redundar em um egoísmo utilitário. A este respeito, já no prefácio, alerta:

Não prometo quadros e novos horários para os ginásios e às escolas técnicas, admiro bem mais a natureza poderosa daqueles que são capazes de percorrer toda a via das profundezas da experiência até o cume dos verdadeiros problemas da cultura, e inversamente destes cumes até os porões dos regulamentos mais áridos e dos quadros mais esmerados; mais fico satisfeito se, estafando-me, tiver subido uma montanha de alguma importância; e se posso gozar de um horizonte mais livre, não poderei jamais neste livro satisfazer os amantes de quadros (NIETZSCHE, 2003a, p. 46).

\section{Nietzsche como educador: a crítica ao eruditismo}

Pensar e agir como animal de rebanho, esconder-se "atrás de costumes e opiniões", ser marcado por profunda preguiça e covardia de se afirmar enquanto único, não se relacionar harmonicamente com a arte, essa rainha afirmadora da unicidade das coisas, que não trata a vida e seus atributos como mercadorias fabricadas em série, tudo isso coaduna com a tipologia eruditista. Tais características, ainda que não se encontrem vinculadas diretamente ao erudito, mas se referem mais amplamente ao próprio modo de existir do ser humano, fazem parte das primeiras linhas de Schopenhauer como educador. De forma incisiva, essa obra apela para a afirmação da singularidade e, para tanto, basta que o homem não seja "indulgente consigo mesmo", o que lhe fará sair da massificação. O erudito, que não é filósofo, 
quando muito historiador da filosofia ${ }^{2}$, a partir disso, por não ser ele mesmo, mas muitos outros e ao mesmo tempo nenhum, torna-se exemplo de massa, também por não lhe ser própria a singularidade. Libertação, eis a palavra que o eruditismo não conhece, e que é fundamental ao ser humano saudável, corajoso. E não conhece a libertação pois "[...] vive nas cadeias da opinião corrente e do medo" (NIETZSCHE, 2003b, p. 139). Por isso Nietzsche insiste que: "Há no mundo um único caminho sobre o qual ninguém, exceto tu, poderia trilhar. Para onde leva ele? Não perguntes nada, deves seguir este caminho" (NIETZSCHE, 2003b, p. 141).

A valorosa busca por ser quem se é não significa que o ser humano chegue a tal ponto de se conhecer por completo, instaurando à perfeição o "Conhece-te a ti mesmo", mas que viva sua peculiaridade, o seu "caso": tudo expressa o que se é. Nesse aspecto é possível ver uma pertinente crítica de Nietzsche ao otimismo socrático que concebe a razão como ápice do humano. Ora:

Como o homem pode se conhecer? Trata-se de algo obscuro e velado; e se a lebre tem sete peles, o homem pode bem se despojar setenta vezes das sete peles, mas nem assim poderia dizer: 'Ah! Por fim, eis o que tu és verdadeiramente, não há mais o invólucro'. É também uma empresa penosa cavar assim em si mesmo e descer à força, pelo caminho mais curto, aos poços do próprio ser (NIETZSCHE, 2003b, p. 141).

A função do verdadeiro educador torna-se a libertação, algo que o eruditismo, não preocupado com os abismos da existência, que trata a tragédia, por exemplo, como mera fonte de erudição, não consegue proporcionar. Schopenhauer, para Nietzsche, é sinônimo de educador e, enquanto tal, de libertador: assim Nietzsche pôde "[...] encontrar-se a si mesmo" (NIETZSCHE, 2003b, p. 142).

\footnotetext{
2 "A história erudita do passado jamais foi o afazer de um verdadeiro filósofo, nem na Índia, nem na Grécia; e um professor de filosofia, quando está ocupado com um trabalho desse gênero, deve se contentar com que se diga dele, no melhor dos casos: 'É um bom filólogo, um bom especialista dos antigos, um bom linguista, um bom historiador' - mas nunca: 'É um filósofo"' (NIETZSCHE, 2003b, p. 212).
} 
Schopenhauer é figura basilar para se entender o jovem Nietzsche, pois desde a sua juventude Nietzsche esperava encontrar "[...] um verdadeiro filósofo a quem pudesse obedecer sem reflexão, porque se teria nele mais confiança que em si próprio" (NIETZSCHE, 2003b, p. 142). Schopenhauer torna-se exemplo de educador, alguém capaz de "[...] ensinar novamente a ser simples e honesto no pensamento e na vida, e portanto intempestivo" (NIETZSCHE, 2003b, p. 146). Schopenhauer, "juiz da autoproclamada cultura que o cercava", é o tipo de sujeito que inspira honestidade, coerência ${ }^{3}$, autenticidade, estilo, unidade, serenidade, vitória, e nada do que diz "[...] nos lembra o erudito de membros naturalmente duros e mal exercitados, de peito estreito e cujo andar é portanto anguloso, confuso ou afetado" (NIETZSCHE, 2003b, p. 147). Segundo Copleston:

Nietzsche deixou-se impressionar pela pintura da vida humana tal como foi apresentada por Schopenhauer, essa sombria pintura que encarna um sério olhar sobre a vida, a visão dum homem que vê o universo como o fenômeno de uma vontade cega, sem um fim, sem um sentido definido - um cenário mutável em que impera a esterelidade, o desânimo, o sofrimento, a morte inevitável, e onde a felicidade não é senão negativa e a beatitude um sonho (COPLESTON, 1953, p. 204).

Um educador filósofo não deve instruir apenas através de seus livros, pois isso é frágil, vago, e se submeter a "opiniões alheias" como fazem os eruditos. Deve, antes e acima de tudo, educar através de seu exemplo de vida. Dessa forma, fica explícita a vinculação nietzschiana a um modo de conceber a filosofia segundo a qual o pensamento não se separa das vivências, o que possui também grande convergência com o modo de ser dos gregos, para os quais o exemplo deveria ser dado “[...] pela expressão do rosto, pela vestimenta, pelo regime alimentar, pelos costumes, mais ainda do que pelas palavras e sobretudo mais do que pela escrita" (NIETZSCHE, 2003b, p. 150). Schopenhauer ${ }^{4}$, com seu modo de vida, influenciou grandemente Nietzsche, e a sua forma de se portar diante do Estado e da

${ }^{3}$ Já o "[...] saber de um imbecil é inútil e incoerente" (MOLIÈRE, 2008, p. 108). 
Universidade dão conta disso: “[...] não dava quase atenção às castas acadêmicas" (NIETZSCHE, 2003b, p. 151) ${ }^{5}$. Schopenhauer, também, era alguém a ser superado como modelo, conforme importante explicação de Sílvio Gallo:

Nietzsche subverte a noção de modelo corrente na pedagogia, em que se entende o modelo como algo a ser copiado. São os ecos platônicos que persistem na educação. Para o filósofo alemão, o modelo é, ao contrário, algo a ser superado. $\mathrm{O}$ modelo é aquele através do qual forjamos nosso disciplinamento, nosso autocontrole, como forma de conquistar a autonomia de pensamento e construir uma criatividade singular. Para o próprio Nietzsche, o modelo foi Schopenhauer; e deseja ele próprio ser um modelo, um filósofo educador para os homens futuros, como evidenciou depois em Ecce homo: como alguém se torna o que é (GALLO, 2006, p. 341).

É possível visualizar claramente a preocupação de Nietzsche com a formação humana. A formação é justamente uma das maiores preocupações nietzschianas e, para tanto, um educador torna-se fundamental. Quando não se tem um modelo o indivíduo vaga a esmo, falta-lhe referência, justamente por carecer de um centro organizador das disposições. Aqui é possível visualizar, também, a importância dada por Nietzsche aos clássicos. Os Gregos e os Romanos, esses sujeitos nobres, sérios, severos, excepcionais, podem se portar como referências, mas, pensa Nietzsche, como estamos distantes destes "na concepção das tarefas da educação". O egoísmo imperou em todos os ambientes e o modo como o eruditismo se posiciona diante da vida é um exemplo disso, aliás, mais a favor da ciência do que da humanidade. O erudito, esse "presunçoso empedernido", é educado por uma abstração inumana, a ciência, e a partir dela ele (des)orienta sua vida e de

\footnotetext{
4 "Para Schopenhauer, por meio do conhecimento (filósofo), da contemplação estética (artista) e da quietude ascética (santo), é possível chegar à suspensão da banalidade do mundo, das ocupações ordinárias" (WEBER, 2011, p. 163).

${ }^{5}$ Todavia, embora esse seja o juízo de Nietzsche, ele é apenas parcialmente correto. Schopenhauer ressentiu-se durante toda a vida por não ter sido incorporado à Universidade. Isso é visível através da obra Sobre a filosofia universitária.
} 
quem mais possa corromper, perverter, sob o princípio obtuso de "quanto mais, melhor". Nietzsche arremata:

A mim me compraz imaginar que os homens ficarão em pouco tempo fartos de leitura, e fartos de escritores; que um dia o erudito refletirá, fará o seu testamento e prescreverá que seu cadáver seja queimado no meio dos livros e sobretudo junto com seus próprios escritos (NIETZSCHE, 2003b, p. 163).

O exemplo-Schopenhauer ${ }^{6}$ soava ao jovem professor Nietzsche como música wagneriana aos seus ouvidos. Mas, por que a indiferença de Schopenhauer para com a Universidade e o Estado ecoou de forma tão grave em Nietzsche? Porque o Estado, essa instituição mantenedora do status quo, da uniformidade, se utilizava da cultura para os seus próprios fins egoístas, utilitários, e o meio pelo qual o Estado se beneficiava por excelência nessa esteira era a Universidade. Como a cultura, para Schopenhauer, deveria ser desinteressada, Nietzsche abraçou tal filosofia, que convergia com a sua. Schopenhauer, esse gênio honesto tal qual Richard Wagner, era o exemplo que faltava a Nietzsche em meio a um ambiente academicista, cheio de aparências:

Tudo isso faz acumular uma nuvem de melancolia na sua fronte: pois estas naturezas odeiam, mais do que a morte, o fato de a aparência ser necessária. E esta tristeza prolongada os torna vulcânicos e ameaçadores. De vez em quando, eles se vingam da sua dissimulação forçada, da circunspecção a que

\footnotetext{
${ }^{6}$ Schopenhauer foi um sujeito solitário que conhecia os homens e não meramente os livros, um pensador que lutou incessantemente contra sua época, o que causou grande admiração de Nietzsche, para, assim, tornar-se o que lhe era próprio: "Se de fato preferirmos considerar todo grande homem como o verdadeiro

filho do seu tempo e como aquele que sofre, em todo caso, com todas as mazelas deste tempo, da maneira

mais intensa e com mais sensibilidade do que todos os homens mais medíocres, o combate deste grande homem contra seu tempo só aparentemente é um combate absurdo e destruidor contra si mesmo" (NIETZSCHE, 2003b, p. 162). A natureza, para Schopenhauer, também é "rigorosamente aristocrática", e

produz poucos gênios ao longo da história. "Ela é tão aristocrática que, em trezentos milhões de seus produtos de fábrica, não surge nem ao menos um espírito verdadeiramente grande" (SCHOPENHAUER, 2001, p. 64).
} 
são obrigados. Eles saem da sua caverna com um semblante terrível, suas palavras e seus atos são então explosões, e é possível que se autodestruam por serem o que são. Schopenhauer viveu assim perigosamente (NIETZSCHE, 2003b, p. 154).

A autenticidade de Schopenhauer ${ }^{7}$, esse gênio legislador, é admirável aos olhos de Nietzsche, pois “[...] ele é o guia que conduz das cavernas da melancolia cética ou da renúncia crítica para as alturas da contemplação trágica, com o céu noturno e suas estrelas no infinito acima de nós" (NIETZSCHE, 2003b, p. 156). Schopenhauer, por ir além das aparências não se trata de ter chegado à coisa-em-si, obviamente, por mais que, de acordo com Schopenhauer, ela se expresse em tudo o que fazemos -, buscava imaginar o pintor se quisesse compreender o quadro. De forma análoga é possível dizer que em $O$ nascimento da tragédia importava a Nietzsche, já influenciado por Schopenhauer, compreender os artistas e os problemas existenciais das tragédias, e não meramente dissecá-los aos moldes estéreis, eruditistas. Por essa razão, afirma Nietzsche: “É preciso imaginar o pintor, caso se queira compreender o quadro - e Schopenhauer sabia disso. Ora, atualmente, toda a corporação de todas as ciências saiu em campo para compreender somente este véu e estas cores, mas não o quadro". (NIETZSCHE, 2003b, p. 156-157).

Por fim, é necessário destacar junto a Ecce Homo:

"Schopenhauer como educador" está inscrita minha história mais íntima, meu vir a ser. Sobretudo meu compromisso!... O que hoje sou, onde estou em uma altura de onde já não falo com palavras, mas com raios -, ó quão longe disso eu ainda estava então! - Mas eu via a Terra - não me enganei um instante sobre caminhos, mares e perigos - e sobre o êxito! A grande paz no prometer, o feliz mirar em um futuro que não permanecerá mera promessa! - Ali cada palavra é vivida, profunda, interior; os sofrimentos

7 "E é assim também que, em primeiro lugar, é preciso sempre interpretar a filosofia de Schopenhauer: de maneira individual, unicamente pelo indivíduo para consigo mesmo, para que se convença da sua própria miséria e de suas necessidades, dos seus limites, e aprenda a conhecer os remédios e as consolações: quer dizer, a abnegação do eu, a submissão a fins mais nobres e sobretudo àqueles da justiça e da piedade" (NIETZSCHE, 2003b, p. 157). 
maiores estão presentes, existem palavras cobertas de sangue. Mas um vento de grande liberdade sopra sobre tudo; a própria ferida não é sentida como obstáculo. - De que modo entendo o filósofo, como um terrível corpo explosivo diante do qual tudo corre perigo, de que modo tanto distancio meu conceito de filósofo que inclui até mesmo um Kant, para não falar dos ruminantes acadêmicos e outros professores de filosofia: sobre isso esse trabalho dá inestimável ensinamento, mesmo concedendo que no fundo não é "Schopenhauer como educador", porém seu oposto, "Nietzsche como educador", que assume a palavra. Considerando que naquele tempo meu ofício era o de erudito, e talvez que eu entendia do meu ofício, não é sem significância um acre fragmento de psicologia do erudito que aparece subitamente nesse trabalho: ele exprime meu sentimento de distância, a profunda segurança sobre o que em mim pode ser tarefa ou apenas meio, entreato e ocupação secundária. É inteligência minha haver sido muitas coisas em muitos lugares, para poder tornar-me um - para poder alcançar uma coisa. Por um tempo eu tive de ser também erudito (NIETZSCHE, 2009, p. 68).

\section{O conhecimento (in)útil: problemas e dilemas acerca do eruditismo}

Nietzsche, enquanto professor de Filologia Clássica da Universidade de Basiléia (1869-1879), manifestava em suas atividades intelectuais um importante compromisso filosófico-pedagógico de contribuir para o desenvolvimento saudável da cultura alemã que, segundo sua perspectiva, se encontrava em uma marcha de decadência de valores ${ }^{8}$. Tal declínio ocorria, grandemente, devido à "cultura erudita", tendência intelectual caracterizada por valorizar apenas a razão em detrimento do instinto. Esse problema se inscreverá em algo muito caro a Nietzsche: a oposição entre arte (vida, instinto) e razão. Quando a vida - "aquele poder obscuro, impulsionador, inesgotável que deseja a si mesmo" - é subjugada, e quando a racionalidade

\footnotetext{
8 "Nietzsche, como educador, não tinha interesse em se tornar um vasculhador de textos antigos, fechado em seu gabinete, nem em criar um círculo de alunos atentos, que seguissem indiferentes à vida que os rodeava. Pretendia, isso sim, incentivá-los a um olhar singular sobre determinada ciência, conduzi-los de modo a poderem criar uma humanidade rica e transbordante de vida. É preciso agir e viver para aprender

e compreender - eis o preceito segundo o qual Nietzsche pretendia educar seus alunos" (DIAS, 1991, p. 26-27).
} 
é posta no pedestal, é porque a barbárie está à porta. Diante disso, é possível perceber que quando Nietzsche desenvolve suas críticas ao eruditismo, ele reflete criticamente sobre a própria cultura moderna e sobre a forma que esta constrói seu ideal de ser humano: tal problema torna-se uma lente potenciadora da visão para a análise da espinhosa e "tão urgente" temática da formação do humano9. Viver adequadamente o presente, criar valores, utilizar-se do conhecimento em prol da vida: nesses aspectos se sintetiza o combate de Nietzsche contra a razão a todo custo incentivada pela modernidade.

Em sua III Consideração Intempestiva Nietzsche compreende treze características que norteiam a tipologia do erudito, sendo possível sintetizálas desta maneira: “[...] o erudito consiste numa rede misturada de impulsos e excitações muito variadas, é um material impuro por excelência" $(\text { NIETZSCHE, 2003b, p. 191) })^{10}$.

Uma boa metáfora para o erudito é compará-lo ao verniz, pois este autonomiza o objeto em relação ao sujeito, algo que torna o conhecimento petrificado, numa prática contínua de deixar o passado, ou o conhecimento de outros povos, sempre válido para o presente, ou seja, a prática eruditista tende a uma covardia e a uma preguiça que podem imobilizar o presente em nome de um passado incessantemente revisitado. $O$ eruditismo, não respondendo adequadamente às questões da vida, cujo conhecimento é sempre contingente, torna-se o senhor do excesso e do supérfluo, pois a decompõe em prol de seus vários interesses unilaterais (especializados), preconizando o desprezo pela grandeza da existência, que exige uma visão orgânica e não uma restrita. Sarah Kofman faz uma importante análise sobre a artificialidade típica do eruditismo:

\footnotetext{
9 Elementos necessários para se formar o gênio: “[...] liberdade viril do caráter, conhecimento precoce dos homens, educação que não visa à formação de um erudito, a ausência de qualquer estreiteza patriótica, de qualquer obrigação de ganhar seu pão, de obediência ao Estado - em suma, liberdade, sempre liberdade: este mesmo elemento extraordinário e perigoso no seio do qual os filósofos gregos puderam crescer" (NIETZSCHE, 2003b, p. 207).

${ }^{10}$ Essa situação é semelhante ao caso do asqueroso inseto Gregor Samsa d'A metamorfose, de Kafka. A personalidade foi tão suprimida a parâmetros externos que ele não se vê em outra função senão servir, obedecer, enfim, submeter-se. Mandar tudo "ao diabo" só é possível em pensamento, pois não se tem nem "[...] dignidade nem opinião própria" (KAFKA, 2010, p. 13).
} 
O excesso de artificialidade é o sintoma de uma cultura decadente e de uma natureza doente, mas que simula saúde e alegria por um turbilhão factício e por um conjunto de adornos destinados a tornar a vida divertida e a tirar o homem de seu tédio. Uma tal cultura, feita de peças e pedaços, é necessariamente efêmera e cética: falta-lhe fé no futuro, em si mesma, ela está voltada para o passado e a morte. Confunde cultura e cultura história, cultura e acumulação heteróclita de conhecimentos (KOFMAN, 1985, p. 86).

Segundo Nietzsche, o erudito “[...] decompõe uma imagem em simples manchas, do mesmo modo como, na ópera, se usa um binóculo para ver a cena e examinar um rosto ou um detalhe da vestimenta, nada inteiro" (NIETZSCHE, 2003b, p. 193). Para Bittencourt:

O eruditismo, por apenas valorizar a quantidade dos conteúdos textuais, não a sua qualidade efetiva e o estímulo para a formação da criatividade e do senso crítico no ato de estudo dos textos, serve de instrumento para as estruturas sociais interessadas na legitimação da ordem instituída e no nivelamento medíocre dos homens. A educação eruditista não se propunha a cultivar as aptidões singulares do indivíduo, mas tão somente a amestrar nos seus parâmetros normativos as potencialidades e anseios pessoais do estudante, dando-lhe a especialização máxima acerca do mínimo, limitando assim os seus horizontes intelectuais e existenciais (BITTENCOURT, 2009, p. 272).

Não se deve pressupor, obviamente, que o conhecimento seja necessariamente algo prejudicial para a vida e que a erudição seja sinônimo necessário de prejuízo (e filisteísmo) para o ser humano, mas o que está em questão é o excesso, que pode tornar o conhecimento uma desvantagem para a existência. É necessário esclarecer que o homem erudito não é necessariamente um filisteu, pois este prospera financeiramente mediante a 
especulação da cultura enquanto que o erudito, em essência, cria um tipo de saber que fica preso a uma falta de experiência com a imanência da vida.

A cultura, sob várias formas, é deturpada pela sociedade, como foi possível visualizar até agora. A massificação da cultura, uma destas formas, é regida grandemente pelo egoísmo dos negociantes, que trata a cultura a partir de sua mesquinharia e utilitarismo: "Daí vêm o princípio e o raciocínio em voga, que dizem mais ou menos isto: quanto mais houver conhecimento e cultura, mais haverá necessidades, portanto, também mais produção, lucro e felicidade - eis aí a falaciosa fórmula" (NIETZSCHE, 2003b, p. 185).

Neste egoísmo a função da educação é contribuir para "a maior quantidade possível de felicidade e lucro". A partir desta lógica o solitário é execrado, banido da sociedade moralmente "correta", pois a cultura visa apenas para satisfazer o lucro:

Vive-se, segundo Nietzsche, num ambiente de pressa generalizada que mata toda a vida contemplativa e tem a exploração econômica pela maior das finalidades a que um ser humano pode se dedicar. Quanto às ciências, em nome de uma especialização do saber que rejeita qualquer diretriz filosófica, entregam o ser humano a uma visão fragmentária da realidade (SANTOS, 1993, p. 39).

Há mais um egoísmo que se serve da ampliação máxima da cultura, qual seja, o egoísmo do Estado, na medida em que esta instituição se crê como fim máximo da cultura. Com tal lógica a cultura torna-se interessada, banalizada, utilitária.

Outro egoísmo que prejudica grandemente a cultura é aquele no qual a cultura “[...] é incentivada por todos aqueles que estão conscientes de possuírem um conteúdo de fealdade e de tédio e que querem mudá-lo por meio de uma pretensa 'bela forma"” (NIETZSCHE, 2003b, p. 187). Esses sujeitos caem em mesquinharias que em nada edificam e em nada cooperam 
com a arte, antes a deterioram pela banalidade e tédio" . Tal egoísmo "[...] é de todos aqueles que têm motivos para se dissimular e se camuflar sob uma forma qualquer" (NIETZSCHE, 2003b, p. 191).

Todavia, ainda há outro egoísmo que prejudica de forma devastadora a cultura, é o egoísmo da ciência, cujos funcionários são os eruditos. Esse egoísmo gera a frieza, a indiferença para com os problemas da existência, tudo é tratado como se fosse um cadáver pronto para ser dissecado. O amor pela ciência torna-se a própria ciência, cria o "homem instrumental", corrói a vida. É quando a vida é subjugada pela razão que um dramático acontecimento se dá: o ser humano se torna coisa, mera coisa. A ciência, em suma, é

[...] fria e árida, ela não tem amor e ignora tudo com um profundo sentimento de insatisfação e nostalgia. Ela é útil apenas a si mesma, tanto quanto é nociva a seus servidores, na medida em que transpõe neles seu caráter próprio e assim ossifica de alguma maneira sua humanidade. Enquanto se entenda essencialmente como cultura o progresso da ciência, ela passará impiedosa e congelada diante do grande homem que sofre, porque a ciência só vê em todo lugar os problemas do conhecimento, e porque, a bem da verdade, no seu mundo, o sofrimento é algo de deslocado e de incompreensível, e neste caso é, no máximo, apenas um problema (NIETZSCHE, 2003b, p. 191).

\section{Conclusão}

É necessário, por fim, destacar a distinção entre "formar" e "informar". O ato de "informar" não é similar a "formar" um indivíduo. O ato de "formar" está relacionado à transmissão de vivências que proporcionam o desenvolvimento cultural e da língua para o indivíduo, possibilitando-lhe adquirir uma consciência crítica em relação ao contexto social no qual ele está inserido, favorecendo assim a sua inserção na vida prática de

\footnotetext{
${ }^{11}$ Os jornalistas são '[...] escravos dos três 'M': o momento, as maneiras de pensar e os modos de agir" (NIETZSCHE, 2003b, p. 189).
} 
transformação e esforço por mudanças na realidade circundante. Formar não é propiciar apenas o desenvolvimento intelectual, mas também, a intuição, a sensibilidade, as vivências - não é algo, assim, utilitário, egoísta. "Informar", no âmbito da ação pedagógica, consiste no ato de se transmitir conteúdos didáticos, sem que neles necessariamente exista uma efetiva relevância orgânica para o estudante - o eruditismo, inegavelmente, é um caso típico de informação -, que recebe continuamente uma grande quantidade de conteúdos que se tornam meros meios para a realização de fins. A "informação" desprovida de reflexão motiva a passividade do estudante, que cria uma espécie de dependência simbólica em face do sistema pedagógico que lhe transmite tais informações, uma verdadeira submissão a parâmetros externos. Para Nietzsche, a educação deve engendrar a vida, pois, do contrário, torna-se mera mantenedora do status quo, cujo resultado é a acriticidade. A prática eruditista, em suma, torna-se acrítica.

\section{Referências}

BITTENCOURT, Renato Nunes. Convergências entre Schopenhauer e Nietzsche na crítica da filosofia acadêmica. Intuitio, v.2, n. 3, 2009, p. 257-278.

COPLESTON, Frederick. Nietzsche: filósofo da cultura. Porto: Livraria Tavares Martins, 1953.

DIAS, Rosa Maria. Nietəsche educador. São Paulo: Scipione, 1991.

GALLO, S. Crítica da cultura, educação e superação de si: entre Nietzsche e Stirner. In: FEITOSA, BARRENECHEA \& PINHEIRO (Orgs.). Nietzsche e os gregos: arte, memória e educação: Assim falou Nietzssche $V$. Rio de Janeiro: DP\&A: Faperj: Unirio; Brasília, DF: Capes, 2006.

KAFKA, Franz. A metamorfose. Trad. de Lourival Holt Albuquerque. São Paulo: Abril, 2010.

KOFMAN, Sarah. "O/Os "conceitos" de cultura nas Extemporâneas ou a dupla simulação". In: MARTON, Scarlett (Org.). Nietæssche hoje? Trad. de Milton Nascimento e Sônia Salztein Goldeberg. São Paulo: Brasiliense, 1985. 
MOLIÈRE. As eruditas. Trad. de Millôr Fernandes. Porto Alegre: L\&PM, 2008.

NIETZSCHE, Friedrich Wilhelm. Ecce Homo. Trad. de Paulo César de Souza.

São Paulo: Companhia das Letras, 2009.

- Sobre o futuro dos nossos estabelecimentos de ensino. Trad. de Noéli Correia de Melo Sobrinho. Rio de Janeiro: Ed. PUC-Rio; São Paulo: Loyola, 2003 a.

III Consideração Intempestiva - Schopenhauer como educador. Trad. de Noéli

Correia de Melo Sobrinho. Rio de Janeiro: Ed. PUCRio; São Paulo: Loyola, 2003b.

SANTOS, Laura. Educação e cultura em Niețsche. Braga: Universidade do Minho, 1993.

SCHOPENHAUER, Arthur. Sobre a filosofia universitária. Trad. de Maria Lúcia de Mello Oliveira Cacciola e Márcio Suzuki. São Paulo: Martins Fontes, 2001.

WEBER, José Fernandes. Formação (Bildung), educação e experimentação em Nietzsche. Londrina: EDUEL, 2011. 